\title{
ATMOSPHERIC ARGON FREE BURNING ARCS WITH A SIMPLIFIED UNIFIED MODEL USING CFD-ARC MODELING
}

\author{
Won-Ho LeE ${ }^{a}$, Jong-Chul LeE ${ }^{b, *}$ \\ ${ }^{a}$ Graduate School of Automotive Engineering, Gangneung-Wonju National University, Republic of Korea \\ ${ }^{b}$ School of Mechanical and Automotive Engineering, Gangneung-Wonju National University, Republic of Korea \\ * corresponding author: jclee01@gwnu.ac.kr
}

\begin{abstract}
Free burning arcs, where the work piece acts as an anode, are frequently used for a number of applications. Our investigation is exclusively concerned with a simplified unified model of arcs and their electrodes under steady state conditions at atmospheric pressure. The model is used to make predictions of arc and electrode temperatures and arc voltage for a $200 \mathrm{~A}$ arc in argon. The computed temperatures along the axis between the cathode tip and the anode surface compare well the measured data.
\end{abstract}

KEYWORDS: free burning arcs, thermal plasmas, arc modeling, arc-electrode interaction, computational fluid dynamics.

\section{INTRODUCTION}

High pressure arcs (also known as thermal plasmas) have been used for cutting, welding, spraying, coating, material heating and melting, lighting, current interruption, and, more recently, for waste disposal, production of fine particles, and thermal plasma vapor deposition [7, 10]. Two methods, one is a DC arc discharge and the other an inductively coupled discharge, are used for generating thermal plasmas, and the DC arc torches have been widely modified due to their simplicity for applications. There are two types of DC arc torches, transferred arc and non-transferred arc, by the configuration of electrodes. It has been studying on high-power DC arc torches for transferred arc (also known as free burning arc) because the arc energy is directly deposited on the treated materials acting as anode with high heat transfer efficiency in free burning arc plasma systems [2].

Thermal plasmas are usually at atmospheric pressure or above. The very frequent collisions between particles of different species within the arc ensure the attainment of a single temperature for all species. For such a plasma, local thermodynamic equilibrium (LTE) usually holds, and computer simulation based on LTE can usually predict satisfactorily the bulk properties (i.e. the arc column) of the arc plasma. For understanding the basic physical processes occurring in free burning arcs there have been conducted several computations with comparing the results to the temperature measurements of an arc column successfully [4, 1]. However, the accuracy of computations is insufficient for the anode region because there is severe departure from LTE. It is very important to predict precisely the temperature of anode region in free burning arcs. The quality and the efficiency of a process depend on the energy flux going into the work piece which acts as anode.
Our investigation is exclusively concerned with argon free burning arcs under steady state conditions at atmospheric pressure by computational fluid dynamics (CFD) analysis. We are also interested in the energy flux and temperature transferring to the anode work piece with a simplified unified model of arcs and their electrodes. In order to determine two thermodynamic quantities such as temperature and pressure and flow characteristics we have modified Navier-Stokes equations to take into account radiation transport, electrical power input and the electromagnetic driving forces with the relevant Maxwell equations. From the simplified self-consistent solution the energy flux to the anode work piece can be derived.

\section{NumERICAL METHODS}

In order to determine two thermodynamic quantities such as temperature and pressure and flow characteristics of the free burning arc under steady state we have modified Navier-Stokes equations to take into account radiation transport, electrical power input and the electromagnetic driving forces with the relevant Maxwell equations,

$$
\begin{gathered}
\frac{1}{r} \frac{\partial}{\partial r}\left[r \rho v \phi-r \Gamma_{\phi} \frac{\partial \phi}{\partial r}\right]+\frac{\partial}{\partial z}\left[r \rho w \phi-\Gamma_{\phi} \frac{\partial \phi}{\partial z} i\right]=S_{\phi}, \\
\frac{1}{r} \frac{\partial}{\partial r}\left(r \sigma \frac{\partial \varphi}{\partial r}\right)+\frac{\partial}{\partial z}\left(\sigma \frac{\partial \varphi}{\partial z}\right)=0
\end{gathered}
$$

where $\rho$ is the gas density, $\Gamma_{\phi}$ the diffusion coefficient, $S_{\phi}$ the source term, $\phi$ the dependent variables, $\mu$ the molecular viscosity, $\kappa$ the thermal conductivity, $\varphi$ the electrostatic potential and $\sigma$ the electrical conductivity (Tab. 17. The subscript 'l' denotes the laminar part of the diffusion coefficient and ' $t$ ' the turbulent part. In the energy conservation equation, $q$ represents the net radiation loss per unit volume and time. 


\begin{tabular}{|l|l|l|l|}
\hline Equations & $\phi$ & \multicolumn{1}{|c|}{$\Gamma_{\phi}$} & \multicolumn{1}{c|}{$S_{\phi}$} \\
\hline Continuity & 1 & 0 & 0 \\
\hline $\begin{array}{l}\text { Axial } \\
\text { momentum }\end{array}$ & $w$ & $\mu_{1}+\mu_{\mathrm{t}}$ & $\begin{array}{l}-\partial p / \partial z+J_{r} B_{\theta} \\
+ \text { viscous terms }\end{array}$ \\
\hline $\begin{array}{l}\text { Radial } \\
\text { momentum }\end{array}$ & $v$ & $\mu_{1}+\mu_{\mathrm{t}}$ & $\begin{array}{l}-\partial p / \partial r+J_{z} B_{\theta} \\
+ \text { viscous terms }\end{array}$ \\
\hline Enthalpy & $h$ & $\left(\kappa_{1}+\kappa_{\mathrm{t}}\right) / c_{p}$ & $\begin{array}{l}\sigma E^{2}-q \\
+\frac{\partial p}{\partial r} v+\frac{\partial p}{\partial z} w \\
+ \text { viscous dissipation }\end{array}$ \\
\hline $\begin{array}{l}\text { Electrostatic } \\
\text { potential }\end{array}$ & $\varphi$ & $\sigma$ & 0 \\
\hline
\end{tabular}

TABLE 1. Definitions of variable, diffusion coefficient, and source term for governing equations.

\begin{tabular}{|l|l|l|l|l|}
\hline & $v(\mathrm{~m} / \mathrm{s})$ & $w(\mathrm{~m} / \mathrm{s})$ & \multicolumn{1}{|c|}{$T(\mathrm{~K})$} & \multicolumn{1}{|c|}{$S_{\phi}$} \\
\hline $\mathrm{DE}$ & $* *$ & $* *$ & 1000 & $\begin{array}{l}\partial \varphi / \partial z \\
=j_{0} / \sigma\end{array}$ \\
\hline $\mathrm{EJ}$ & 0 & $w_{\text {in }}$ & 1123 & $\partial \varphi / \partial z=0$ \\
\hline $\mathrm{KG}$ & $*$ & $*$ & $\partial h / \partial \mathrm{n}=0$ & $\partial \varphi / \partial \mathrm{n}=0$ \\
$\mathrm{GH}$ & & & & \\
\hline $\mathrm{BC}$ & 0 & $\partial w / \partial r=0$ & $\partial h / \partial r=0$ & $\partial \varphi / \partial r=0$ \\
\hline $\mathrm{CD}$ & $* *$ & $* *$ & $\partial T / \partial r=0$ & $\partial \varphi / \partial r=0$ \\
\hline $\mathrm{EF}$ & 0 & 0 & --- & --- \\
$\mathrm{FC}$ & & & & $\varphi=$ const. \\
\hline $\mathrm{BH}$ & 0 & 0 & --- & --- \\
\hline $\mathrm{HI}$ & $* *$ & $* *$ & 1000 & \\
$\mathrm{AI}$ & & & & \\
\hline
\end{tabular}

TABLE 2. Boundary conditions for the temperature and the electric potential.

The viscous terms in the momentum and energy equations which are not included in the diffusion coefficient are treated as their respective source terms. Ohmic heating $\sigma E^{2}$ is providing heat source and Lorentz force $\mathbf{J} \times \mathbf{B}$ is providing momentum source. In addition, the current density and the magnetic field are calculated from the electrostatic potential and Ampere's law, respectively, and can be written as

$$
\begin{gathered}
j_{r}=\sigma \frac{\partial \varphi}{\partial r}, \quad j_{z}=\sigma \frac{\partial \varphi}{\partial z}, \\
\frac{1}{r} \frac{\partial}{\partial r}\left(r B_{\theta}\right)=\mu_{0} j_{z},
\end{gathered}
$$

where $B_{\theta}$ is the azimuthal component of the magnetic field and $\mu_{0}$ the permeability of free space.

Thermodynamic and transport properties such as density, enthalpy, constant pressure specific heat, viscosity, electrical and thermal conductivities, and optically thin radiation losses required for this calculation are strongly dependent on temperature and pressure. The data adopted in this study have been taken from Refs. [8, 9].

The boundary conditions required for the solution of Eqs. 1 and 2 are listed in Tab. 2. From Tab. 2 , $j_{0}$ is the total current divided by the uniform cross section of the cathode and 'n' denotes the normal direction to a surface. Symbol '*' denotes the pressure is

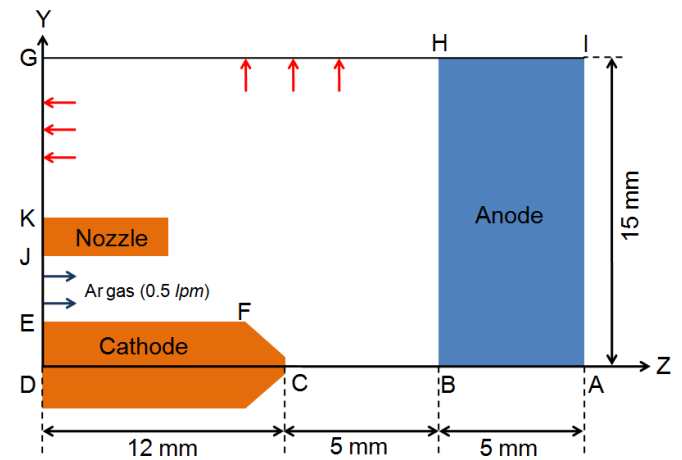

FIGURE 1. Schematic of a free-burning arc plasma system for experiments performed by Haddad and Farmer [3].

set at $0.1 \mathrm{MPa}$ and symbol '**' denotes the locations where velocities do not need to be specified. The given inlet flow conditions correspond to those investigated by Haddad and Farmer which is $0.5 \mathrm{l} / \mathrm{min}$ [3]. Symbol '---' indicates that the solid surface temperature is calculated.

Energy transport within the solid electrodes is governed by conduction. The energy conservation equation for steady state case can be written as

$$
-\nabla \cdot\left(k_{\mathrm{m}} \nabla T_{\mathrm{m}}\right) \text {, }
$$

where $k_{\mathrm{m}}$ and $T_{\mathrm{m}}$ are respectively the thermal conductivity and temperature of the electrode material.

\section{RESUlts AND Discussion}

The argon arc burns at atmospheric pressure in a $5 \mathrm{~mm}$ gap between a shaped cathode and a water-cooled copper anode as shown in Fig. 1 (commonly known as the point-plane arc), where the key locations in the computational domain are indicated by letters A to I. The tungsten cathode has a rod diameter of $3.2 \mathrm{~mm}$ and its tip has a full conical angle of $60^{\circ}$ [3]. Temperature distribution in the arc can be predicted by including the electrodes in the solution domain without the inclusion of the non-LTE sheaths.

The experimental arrangements and the experimentally measured arc temperature of Farmer and Haddad [3] have become a benchmark for theoretical studies of argon free burning arc. The argon gas with a temperature of $1000 \mathrm{~K}$ and a pressure of $0.1 \mathrm{MPa}$ is fed in through an annular nozzle at a fixed flow rate of $0.5 \mathrm{l} / \mathrm{min}$. The comparison between the simulation result and the experimental measurement was given for the arc current of $200 \mathrm{~A}$.

The two-dimensional temperature and axial velocity fields are shown in Fig.2. The temperature in the arc region presents the typical bell shape of high intensity arcs. The present results for $200 \mathrm{~A}$, compared with those of [3, 11] given in brackets, were maximum arc temperature $24300 \mathrm{~K}(23700 \mathrm{~K})$, maximum axial velocity $500 \mathrm{~m} / \mathrm{s}(500 \mathrm{~m} / \mathrm{s})$ and arc voltage $10.5 \mathrm{~V}(12.9 \mathrm{~V})$. The temperature near the cathode is high because of contraction of arc column 
(a) Temperature

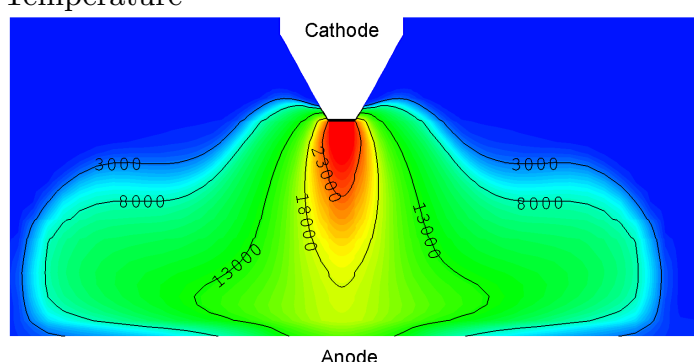

(b) Axial velocity

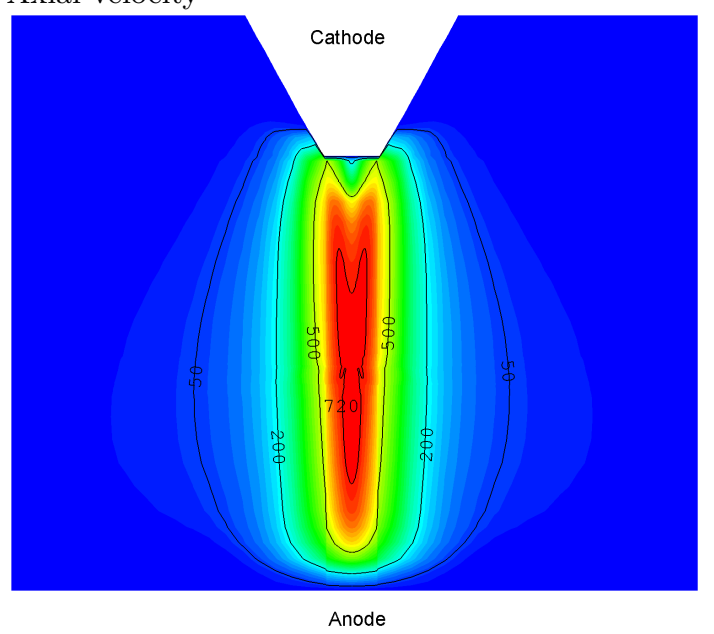

Figure 2. Temperature [unit: $\mathrm{K}$ ] and axial velocity [unit: $\mathrm{m} / \mathrm{s}$ ] fields for a $200 \mathrm{~A}$ free burning argon arc at $1 \mathrm{~atm}$ under the experiment conditions of Haddad and Farmer [3].

near the cathode spot. The magnetic pinch effect induced by the arc current creates an over pressure near the cathode. Since the arc temperature is very high, a small pressure difference will accelerate the arcing gas to a high speed, typically a couple of hundred meters per second. There is a very thin, high velocity core (Fig. 2p) in the arc column. The half width of the radial profile of axial velocity, defined as the radial position at which the velocity is reduced to $50 \%$ of the axis velocity at the mid-gap ( $2.5 \mathrm{~mm}$ from the cathode tip), is $0.4 \mathrm{~mm}$. Such a narrow high velocity core is typical of laminar arc plasma flow for which viscous effects are negligible. The energy transport is dominated by convection and radiation in the core region near the axis. However, the turbulent model is essential to predict flow characteristics near cathode and anode due to separation and stagnation, respectively [5]. According to the above comparative data, our simulation results match well with other measured and predicted data given by [3, 11].

Figure 3 shows the detailed comparisons with the temperatures along the axis. The experimental data of [3] for an arc under same conditions are also plotted in Fig. 3. The temperature near the cathode is higher than that near the anode because of contraction of arc column near the cathode spot. The differences between these two sets of results are not significant and there is good agreement.

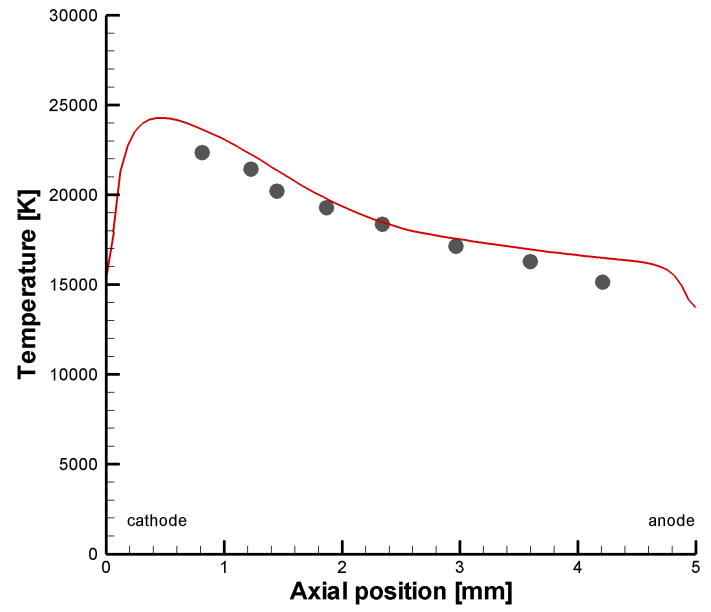

Figure 3. Comparison of the predicted temperature (solid lines) along the axis between the cathode tip and the anode surface with the experiment results (symbols) of Haddad and Farmer [3] for a $200 \mathrm{~A}$ argon arc at $1 \mathrm{~atm}$.

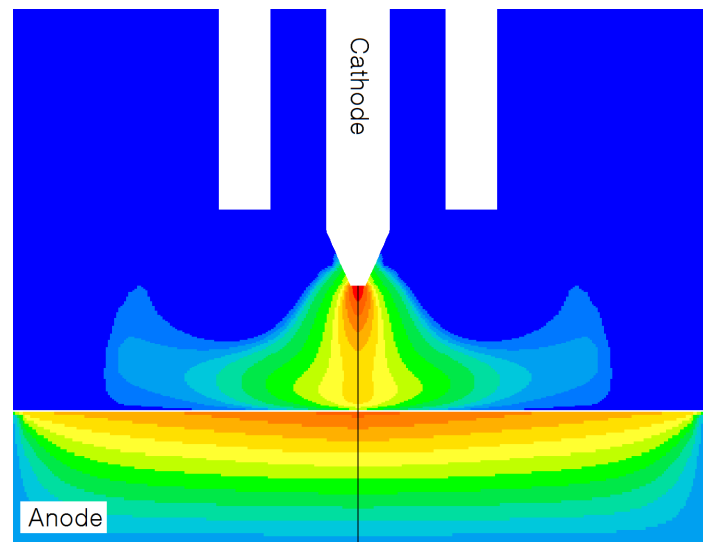

Figure 4. Temperature and isotherm lines for a $200 \mathrm{~A}$ argon arc at $1 \mathrm{~atm}$. In anode, outer isotherm, 1400K, interval $25 \mathrm{~K}$ for the temperature range $1000 \div 1400 \mathrm{~K}$, whereas interval $1000 \mathrm{~K}$ is for the temperature range $1000 \div 23000 \mathrm{~K}$ in arc column.

In Fig. 4 we now present the computed isotherm lines for the part of anode. The temperature reaches a maximum of $1365 \mathrm{~K}$ in the anode, which shows good agreement with the results by Lago et al. 6]. From this value, we can predict the presence of a liquid metal pool in the anode and the presence of metal vapours in the plasma because it is greater than the melting point of cooper $(1357 \mathrm{~K})$. Therefore, further investigation should include the modelling of $\mathrm{Cu}$ evaporation from anode and non-LTE situation near electrode for more realistic calculations.

\section{Conclusions}

In this study, we have carried out computational investigation of argon free burning arcs under steady state conditions at atmospheric pressure with a simplified unified model of arcs and their electrodes. It was found that the computed temperatures along the axis be- 
tween the cathode tip and the anode surface show good agreement with those measured by Haddad and Farmer 3. For the maximum axial velocity, the predicted value of $750 \mathrm{~m} / \mathrm{s}$ from our simulation results matches well with the predicted value given by Zhu et al. [11. In addition to the arc column, the temperature distribution in the anode also shows good agreement with the results by Lago et al. 6]. This knowledge of free burning arc features can play a role in developing the atmospheric plasma systems, however, further investigation should include the modelling of $\mathrm{Cu}$ evaporation from anode and non-LTE situation near electrodes for more realistic calculations.

\section{ACKNOWLEDGEMENTS}

This research was supported by Basic Science Research Program through the National Research Foundation of Korea (NRF) funded by the Ministry of Education, Science and Technology (2012-0007808).

\section{REFERENCES}

[1] R. Bibi, M. Monno, M. I. Boulos. Numerical and experimental study of transferred arcs in argon. $J$ Phys D: Appl Phys 39(15):3253-3266, 2006.

[2] W. H. Gauvin. Some characteristics of transferred-arc plasmas. Plasma Chem and Plasma Processing 9(1):65S-84S, 1989.

[3] G. N. Haddad, A. J. D. Farmer. Temperature determinations in a free-burning arc. I. Experimental techniques and results in argon. J Phys D: Appl Phys 17(6):1189-1196, 1984.
[4] J. Haidar. A theoretical model for gas metal arc welding and gas tungsten arc welding. J Appl Phys, 84(7):3518-3529, 1998.

[5] Y. J. Kim, J. C. Lee. Computational investigation on the disturbed thermal plasma for improving the reliability of electrostatic diagnosis. Vacuum 84(6):766-769, 2010.

[6] F. Lago, J. J. Gonzalez, P. Freton, A. Gleizes. A numerical modelling of an electric arc and its interaction with the anode: Part I. The two-dimensional model. J Phys D: Appl Phys 37(6):883-897, 2004.

[7] S. Liau. Computer simulation of high pressure non-equilibrium plasma. Department of Electrical Engineering, University of Liverpool, England, 2005. Dr. Thesis.

[8] J. Menart, J. Heberlein, E. Pfender. Theoretical radiative emission results for argon/copper thermal plasmas. Plasma Chem and Plasma Processing 16(1):245S-265S, 1995.

[9] A. B. Murphy. A comparison of treatments of diffusion in thermal plasmas. J Phys D: Appl Phys 29(7):1922-1932, 1996.

[10] E. Pfender. Thermal plasma technology: Where do we stand and where are we going? Plasma Chem and Plasma Processing 19(1):1-31, 1999.

[11] P. Zhu, J. J. Lowke, R. Morrow. A unified theory of free burning arcs, cathode sheaths and cathodes. J Phys D: Appl Phys 25(8):1221-1230, 1992. 